\title{
STUDIES ON THE MALE STERILITY IN THE SILKWORM, BOMBYX MORI L., INDUCED BY APHOLATE
}

\author{
ETSUJI SUGAI AND CHISATO HIRANO*
}

\begin{abstract}
Faculty of Agriculture, Tokyo University of Agriculture and Technology, Koganei, Tokyo and *National Institute of Agricultural Sciences, Nishigahara, Tokyo
\end{abstract}

Reccived Junc 2, 1965

Because of the economic importance for the biological control of insects, a number of attempts have been undertaken to sterilize them by radiations and chemicals. Among such chemicals, it has recently been reported that a remarkable sterility was induced when apholate, one of the alkylating agents, had been administered to the insects (LaBrecque 1961; Chamberlain 1962; Harris 1962). However, very little information has been published so far regarding the histological and cytological mechanism by which the insect sterility is brought about. In order to carry out this work more efficiently, it is necessary to elucidate accurately the changes that occur in germ cells after the treatment. Furthermore, experiments in this area may offer an excellent opportunity to explore some information in relation to the effect of the chemical on living cells.

In this paper, an oral administration of apholate was applied to the male silkworm larvae and studies were performed on the resulting induced sterility, with special consideration on cytological consequences after the treatment.

\section{MATERIAL AND METHODS}

In the present experiment a $\mathrm{F}_{1}$ hybrid, N. $106 \times$ Daizô was used as material. Apholate $(2,2,4,4,6$, 6-hexakis (1-aziridinyl)-2, 2, 4, 4, 6, 6-hexahydro-1, 3, 5, 2, 4, 6-triazatriphosphorine-the chemical name) used in this experiment is one of insect chemosterilants produced in U.S.A., and has the structural formula given in the following.

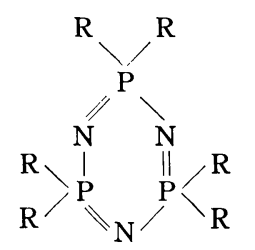

Where $\mathrm{R}$ is-<smiles>CN1CC1</smiles>

After recrystallization, the apholate was dissolved in distilled water at concentrations of $100 \mu \mathrm{g}, 300 \mu \mathrm{g}$ and $500 \mu \mathrm{g}$ per $0.1 \mathrm{ml}$. In order to insure accurate dose to be administered, those were orally injected into the midgut of the larva. The treated larvae were 
reared in air conditioned room at $24^{\circ} \mathrm{C}$ throughout the remainder of their life cycle. They were mated after emergence to untreated females. After pigmentation of deposited eggs the percentage of unfertilized eggs was calculated which was used as a criterion of the induced sterility. In parallel to these experiment, the cytological observation was made on the testes which were fixed with Zenker's, Bouin or Carnoy fluids at appropriate time intervals after the treatment and embedded in paraffin, cut at $7.20 \%$ in thickness, and stained with Mayer's acid hemalaum.

\section{EXPERIMENTAL RESULTS}

\section{Stages of treatment and doses of the chemical for induction of the sterility}

As the first step, a relationship between the developmental stages of the insect and concentrations of the chemical was studied. Three different doses of apholate were orally administered to the larvae either on the 1st day or 5th day of the fifth instar. The results obtained are shown in Table 1.

Table 1. Administration of apholate to the male larvae on the 1st and 5 th day of the 5 th instar and \% of unfertilized eggs produced (N. $106 \times$ Daizô)

\begin{tabular}{|c|c|c|c|c|c|c|}
\hline $\begin{array}{l}\text { Stage of } \\
\text { treatment }\end{array}$ & $\begin{array}{c}\text { Doses } \\
\text { per } \\
\text { insect }\end{array}$ & $\begin{array}{l}\text { No. of } \\
\text { moths } \\
\text { examined }\end{array}$ & $\begin{array}{l}\text { Total } \\
\text { No. of } \\
\text { eggs }\end{array}$ & $\begin{array}{l}\text { No. of } \\
\text { fertilized } \\
\text { eggs }\end{array}$ & $\begin{array}{l}\text { *No. of } \\
\text { unfertilized } \\
\text { eggs }\end{array}$ & $\begin{array}{c}\% \text { of } \\
\text { unfertilized } \\
\text { eggs }\end{array}$ \\
\hline \multirow{3}{*}{$\begin{array}{l}1 \text { st day } \\
\text { of } 5 \text { th } \\
\text { instar }\end{array}$} & $100 \mu \mathrm{g}$ & 15 & 6,188 & 3,425 & 2,763 & $44.6 \%$ \\
\hline & 300 & 21 & 7,180 & 21 & 7,156 & 99.7 \\
\hline & 500 & 17 & 6,439 & 13 & 6,426 & 99.7 \\
\hline \multirow{3}{*}{$\begin{array}{l}5 \text { th day } \\
\text { of } 5 \text { th } \\
\text { instar }\end{array}$} & 100 & 21 & 10,063 & 9,825 & 238 & 2.3 \\
\hline & 300 & 18 & 7,154 & 6,876 & 257 & 3.5 \\
\hline & 500 & 14 & 5,643 & 5,120 & 523 & 9.7 \\
\hline \multicolumn{2}{|c|}{ Control } & 14 & 7,775 & 7,588 & 187 & 2.4 \\
\hline
\end{tabular}

* Since the oviposition of the females mated with sterilized males is remarkably suppressed at the beginning, they were allowed to oviposit continuously for 1 week.

From the Table, it may be seen that, at the 1st day of the fifth instar, apholate treatment with higher doses than $300 / \mathrm{g}$ per insect is clearly effective for sterilizing the insect. Treatment at the 5th day of the same instar, however, did not show up any pronounced sterility, except for the experimental group treated with $500 \mu \mathrm{g}$ per insect in which a slight increase of unfertilized eggs was observed.

2. Cytological evidence for induction of male sterility

In order to elucidate the induction mechanism of the male sterility produced by apholate, cytological observations were made on the treated testes. The results described here concern cells treated with $300 \mu \mathrm{g}$ per insect. 


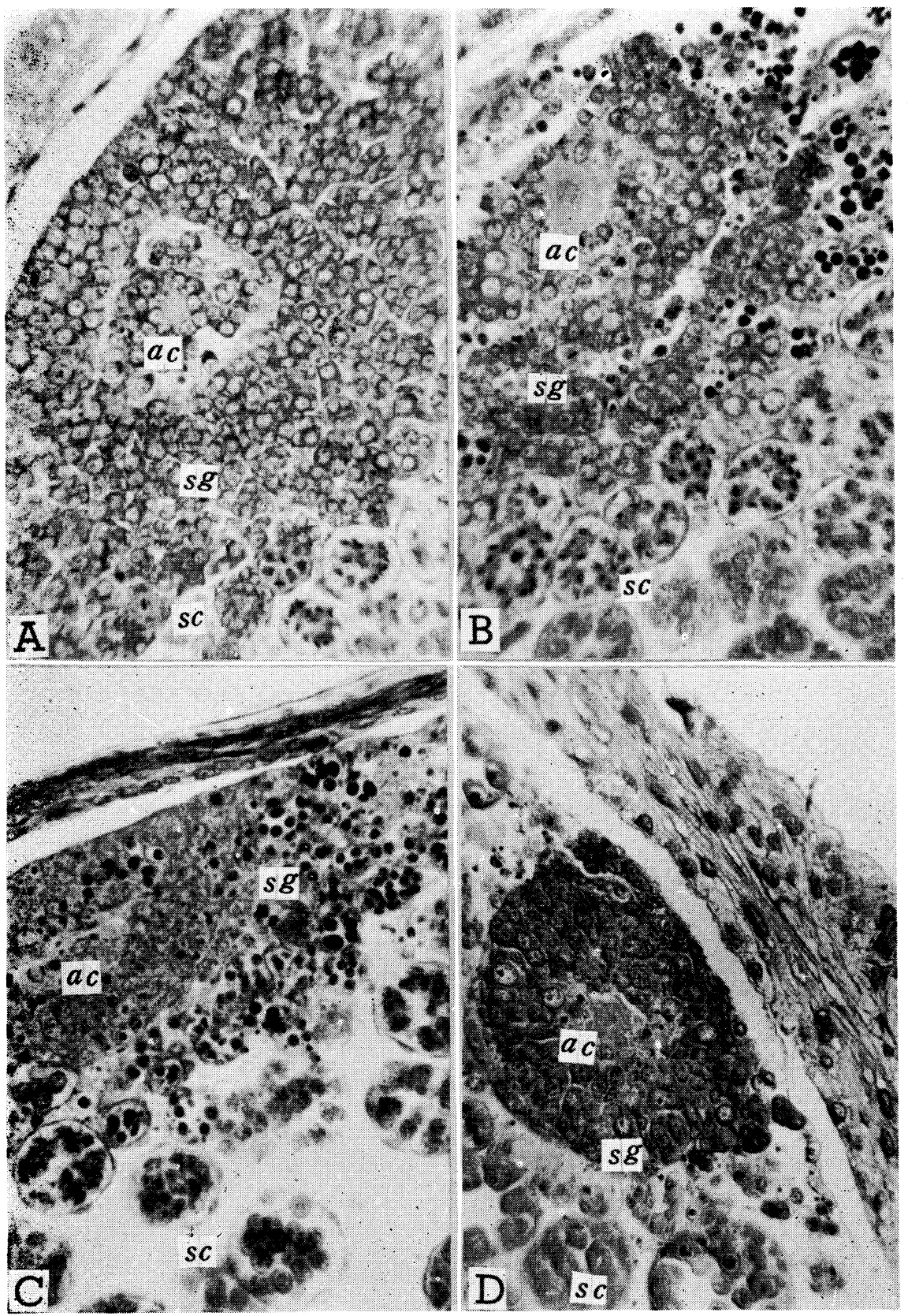

Fig. 1. Distal part; of testicular follicles treated with apholate observed $48 \mathrm{hrs}(\mathrm{B}), 72 \mathrm{hrs}$ (C) after administration and those of untreated control (A). See necrotic degeneration of spermatogonia (Black spots) in treated testes. Treated at the beginning of the fifth instar and observed at 10 days of pupa (D). Note depletion of spermatogonia and commencement of their regeneration. $\times 400$.

Abbreviations. ac; apical cell. sg; spermatogonia. sc; spermatocytes. aab ; apholate induced abnormal sperm bundle. eb; eupyrene sperm bundle. ab; apyrene sperm bundle. 
(1) Treatment at early fifth instar

(a) $12.48 \mathrm{hrs}$ after the treatment: In the testes of the larvae, at the time of the treatment, a large part of the testicular follicles were filled with spermatocytes at various stages, from the early prophase to the metaphase of the first meiotic division and in the apex of each follicle many spermatogonia were proliferating around the apical cells. $12 \mathrm{hrs}$ after the administration, no morphological difference in the development of the spermatogenic cells was observed between treated and untreated larvae. At $24 \mathrm{hrs}$ after the treatment, however, there appeared some late spermatogonia which showed abnormal stainability for hemalaum. As time elapsed, these abnormal spermatogonia increased in number. Thus, by $48 \mathrm{hrs}$ after the treatment, a considerable number of cells at the late spermatogonial stage were undergoing a pronounced pycnotic degeneration, yet no detectable changes were shown in the apical cells, primary spermatogonia and other spermatogenic cells such as spermatocytes and young spermatids. They still developed normally except for some chromosome aberrations occasionally shown at the meiotic metaphase (Fig. $1 \mathrm{~B}$ ).

(b) $72120 \mathrm{hrs}$ after the treatment: At $72 \mathrm{hrs}$ after the treatment, the destruction of spermatogonia was still proceeding. The pycnotic figures and disorganization of the cells were also occurring in the younger spermatogonial region located adjacent to the apical cells (Fig. 1C). Thus, at $120 \mathrm{hrs}$ after the administration, as the result of the

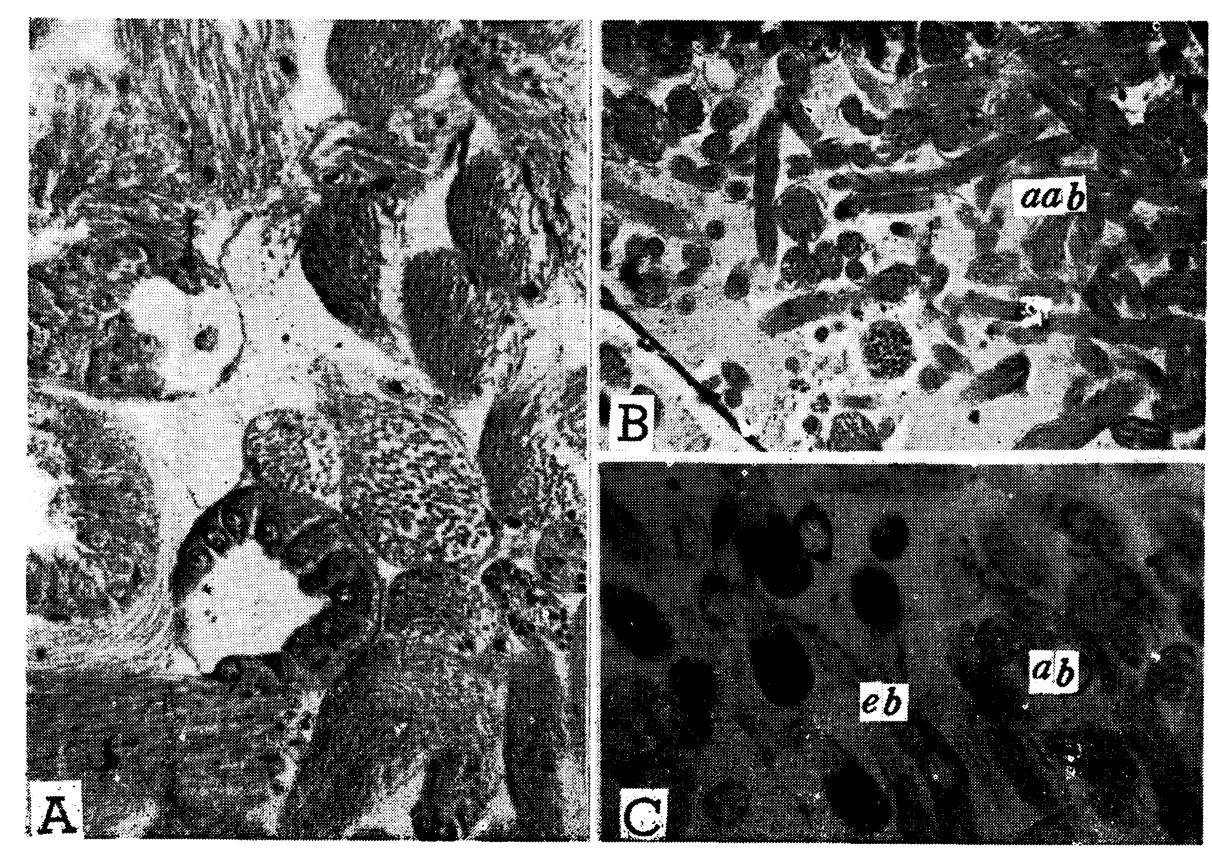

Fig. 2. Necrotic figures of spermatidal cells observed in spermiogenesis (A), abnormal spermatozoa produced in treated testes (B) and the control (C) observed end of the pupal period. $\times 400$. 
disappearance of degenerated cells the spermatogonial regions were almost completely gone leaving the apical cells and primordial germ cells intact. No young spermatocyte remained in this region. However, there were fully developed spermatocytes and spermatids in spermiogenesis. In these fully developed spermatocytes and spermatids some pycnotic figures were occasionally observed (Fig. 2 A). Yet, it appeared likely that many of them were able to transform into spermatozoa, showing morphological abnormalities such as a decreasing of stainability and disarrangement of nuclei in the bundle (Fig. 2 B).

(c) Pupal period: At the 10th day of pupal period, a greater part of the testicular follicles were filled with abnormal sperm bundles mentioned above. Cells showing pycnotic figures were not visible, and regeneration of spermatogonia had already commenced very slowly (Fig. 1D). On the other hand, in the testes of untreated insects at this stage, not only eupyrene sperm bundles but also a number of apyrene sperm bundles had been already produced whereas they were scarcely observed in those of treated insects.

(d) After emergence: Some of the abnormal spermatozoa caused by the apholate treatment, transfered into the vas efferens testes through the membrana basilalis but it was not detected whether they were ejaculated into the reproductive organs of female insect or not.

\section{(2) Treatment at the middle of the fifth instar}

At this stage, a number of germ cells have already differenciated into spermatids and young spermatozoa. By the administration of the chemical, the cells situated at the late spermatogonial region were readily killed at the same rate as those treated at the beginning of the same instar. However, no detectable cytological changes were observed in the cells treated as spermatids and spermatozoa and they maintained normal growth without showing any morphological abnormalities in subsequent development. At the end of the pupal period, a number of eupyrene spermatozoa were observed. From these results, it was presumed that spermatogenic cells after meiotic division were fairly resistant to the chemical.

\section{DISCUSSION}

Concernig the effectiveness of chemical compounds on the reproduction of the insects, it has been evaluated that two types of compounds, antimetabolites and alkylating agents, have shown to be the most promising. Goldsmith and Frank (1952) have reported that the sterility in the Drosophila melanogaster was induced by oral administration of aminopterin, the folic acid antagonist. In the house fly Musca domestica, Norman Mitlin et al (1957) have attempted an induction of sterility using aminopterin, nitrogen mustard, colchicine, podophylotoxin and reported that a pronounced prevention of ovarian development and some sterility are shown in the female but 
the fertility of male flies is in no way affected by the feeding of such chemicals. One of present authors Sugai tried to perform, using such chemicals as described above, an induction of male sterility in the silkworm, Bombyx mori, but failed because of a high toxity of the chemical to the insect resulting in high mortality. However, evidence has been provided recently that the treatment of various kinds of insects with apholate resulted in complete sexual sterility (LaBrecque 1961: Chamberlain 1962: Harris 1962).

In the experiment reported here, a remarkable sterility of the male silkworm was obtained when the appropriate doses of apholate were administered to the larvae at the beginning of the fifth instar, yet, little effect was shown in the case of the treatment at the middle of the same instar. According to Lindquist et al (1964), the end effect of apholate treatment in male boll weevils, Anthonomus grandis Boheman may have been directed to the spermiogenic transformations and/or meiotic II division. In the silkworm males, the occurrance of sterility caused by apholate was interpreted from the cytological detection as being due to the following two causes: (1) Spermatocytes which ordinarily would be functional eupyrene spermatozoa in the future if not treated, transformed into functionless abnormal spermatozoa. (2) Almost all of the spermatogonia were readily killed, and the succession of spermatogenesis was halted. However, because of a high resistance of spermatids and spermatozoa to the chemical, none of the effectiveness was indicated at the middle of the fifth instar.

As to reason why the apholate gives rise to the death of spermatogonia selectively and induced abnormality of spermatogenic cells intrinsically, no adequate information is available in the present experiments. In general, however, it has been known that the alkylating agent referred to as radiomimetic compounds, replace hydrogen with an alkyl group in fundamental genetic material with an effect similar to that of irradiation (Alexander 1960). In elucidating the cytological mode of action of this chemical, it has been proved in the present experiment that the necrotic cell death of spermatogonia appears first after the treatment, and spermatocytes at the time of treatment transform into functionless abnormal spermatozoa whereas both spermatids and spermatozoa are highly resistant. These effect, at least in superficial appearance, are similar to those well established by gamma irradiation (Sado 1961). However, in the reproductive cells of this insects, an extremely higher sensibility was shown in the male than female when they were irradiated, while approximately the same or slightly higher effectiveness was manifest $\epsilon \mathrm{d}$ in the female compared to the male in the case of apholate treatment. A publication of these findings will be made elsewhere. On the other hand, the toxic effects of this chemical on the physiology of this insect were not so strong. Therefore, the insects treated with $300 \%$ g of apholate developed, as well as those untreated without showing any abnormality in external appearance. However, in the larvae administered with $500 \mu \mathrm{g}$ per insect, the development of their wings was so severely arrested that they became almostly wingless when they emerged. Furthermore, an incidence of the 
disease of polyhedora which is considered to be attributable to apholate treatment was observed.

\section{SAMMARY}

This report dealt with the effectiveness of apholate, one of alkylating agents, in sterilising the male of the silkworm, Bombys mori $L$., with special consideration on cytological consequences after treatment. When the male larvae were administered at the 1st day of the fifth instar with doses more than $300 \mu \mathrm{g}$ per insect they were almost completely sterilized, while no remarkable sterility was shown in the case of the treatment at the middle of the same instar with the same doses of the chemical. From the cytological observations, it has been elucidated that the necrotic cell death of spermatogonia has occurred first after treatment and spermatocytes at the time of treatment transformed into functionless abnormal spermatozoa whereas both spermatids and spermatozoa were highly resistant. From these results, the occurrance of male sterility caused by apholate is interpreted as being due to the transformation of treated spermatocytes into functionless spermatozoa and death of spermatogonia by which the succession of spermatogenesis is halted.

\section{LITERATURE CITED}

Alexander Peter, 1960 Radiation-imitating chemicals. Scientific American 202: 99-108.

Chamberlain, W.F., 1962 Chemical sterilization of the screw-worm. J. Econ. Entomol. 55: 240-248.

Goldsmith, E. O., and Frank, I., 1952 Sterility in the female fruit fly, Drosophila melanogaster, produced by the feeding of a folic acid antagonist. Am. J. Physiol. 171: 726-727.

Harris, R. L., 1962 Chemical induction of sterility in the stable fly. J. Econ. Entomol. 55: 882-885.

LaBrecque, G.C., 1961 Studies with three alkylating agents as house fly sterilants. J. Econ. Entomol. 54: 648-689.

Lindquist, D. A., L. J. Gorzycki, M. S. Mayer, A. L. Scales, and T. B. Daich, 1964 Laboratory studies on sterilization of the boll weevil with apholate. J. Econ. Entomol. 57: 745-750.

Norman Mitlin, B. A. Butt, and Thomas J. Shortino, 1957 Effect of mitotic poisons on house fly oviposition. Physiol. Zool. 30: 133-136.

Sado, T., 1961 Spermatogenesis of the silkworm and its bearing on radiation induced sterility. Japan. J. Genetics 36 Suppl. 1: 137-151. 